\title{
Combat blast injuries: Injury severity and posttraumatic stress disorder interaction on career outcomes in male servicemembers
}

\author{
Susan L. Eskridge, PT, PhD; ${ }^{*}$ Caroline A. Macera, PhD; ${ }^{2-3}$ Michael R. Galarneau, MS; ${ }^{1}$ Troy L. Holbrook, PhD; ${ }^{4}$ \\ Susan I. Woodruff, PhD; ${ }^{1,5}$ Andrew J. MacGregor, PhD; ${ }^{1}$ Deborah J. Morton, PhD; ${ }^{6}$ Richard A. Shaffer, PhD ${ }^{2-3}$ \\ ${ }^{1}$ Department of Medical Modeling and Simulation, Naval Health Research Center, San Diego, CA; ${ }^{2}$ Department of \\ Defense HIV/AIDS Prevention Program, Naval Health Research Center, San Diego, CA; ${ }^{3}$ Graduate School of Public \\ Health and ${ }^{4}$ School of Social Work, San Diego State University, San Diego, CA, ${ }^{5}$ EPI-SOAR Consulting Inc, San \\ Diego, CA; ${ }^{6}$ Division of Epidemiology, Department of Family and Preventive Medicine, University of California, San \\ Diego, $C A$
}

\begin{abstract}
The purpose of this study was to describe career performance outcomes after combat blast injury and to examine the relationship between the injury severity and type of military discharge. A retrospective cohort study of 4,255 male servicemembers injured in a combat blast as a part of Operation Iraqi Freedom was completed. In the total sample, 37.8\% experienced a normal discharge and $8.3 \%$ had an early discharge. Of the 2,229 members who had a discharge code, $29.8 \%$ experienced a disability discharge. Both early attrition and disability discharge proportions were higher in those with posttraumatic stress disorder (PTSD) than in those without PTSD. There was a significant interaction between PTSD and injury severity in the discharge disability outcome. In those without PTSD, there was a dose-response relationship between injury severity and disability discharge. In those with PTSD, injury severity predicted disability discharge. The relationship between injury severity and disability discharge was less striking in servicemembers with PTSD than without PTSD. The effect of PTSD and injury severity on career performance outcomes after blast injuries should be factored into outcome planning.
\end{abstract}

Key words: blast injury, career performance outcomes, combat blast, functional outcomes, injury severity, mental health, military discharge, Operation Iraqi Freedom, polytrauma, posttraumatic stress disorder.

\section{INTRODUCTION}

Blasts are the most common mechanism of injury in Operation Iraqi Freedom (OIF) and Operation Enduring Freedom (OEF), with up to 80 percent of all injuries caused by blasts [1-2]. The causes of blasts include improvised explosive devices (IEDs), grenades, land mines, mortars, rocket-propelled grenades (RPGs), and aerial bombs, with the majority of blasts caused by IEDs [1-3]. Blast

\footnotetext{
Abbreviations: AIS = Abbreviated Injury Scale, CHAMPS = Career History Archival Medical and Personnel System, CI = confidence interval, EMED = Expeditionary Medical Encounter Database, ICD-9 = International Classification of Diseases9th Revision, IED = improvised explosive device, ISS = Injury Severity Score, MTF = medical treatment facility, NHRC = Naval Health Research Center, OEF = Operation Enduring Freedom, OIF = Operation Iraqi Freedom, OR = odds ratio, PTSD = posttraumatic stress disorder, RPG = rocket-propelled grenade, TBI = traumatic brain injury.

*Address all correspondence to Susan L. Eskridge, PT, PhD; Naval Health Research Center, 140 Sylvester Rd, San Diego, CA 92106; fax: 619-553-8551.

Email: susan.eskridge@med.navy.mil

http://dx.doi.org/10.1682/JRRD.2012.01.0004
} 
injuries involve multiple mechanisms of injury that range from mild severity to a fatality, and they can have an effect on nearly any body system and anatomical region [4-7]. Some of the most common injuries include traumatic brain injuries (TBIs), fragment wounds to limbs and torso, and tympanic membrane ruptures [1-4].

With a greater percentage of wounded servicemembers surviving battle injuries in OIF/OEF than in any other previous conflict, understanding the outcomes and the potential risk factors for adverse outcomes is important in providing support after the injury. Because of the extreme violence of blast and its characteristic effects, polytrauma is more common in blast injuries than in injuries from other mechanisms and produces an array of injury profiles $[4,8]$. Polytrauma creates a unique challenge for medical care and rehabilitation because of the variable and complex nature of these injuries [9-11]. After rehabilitation, long-term impairments from blast injuries can continue to affect the functioning of servicemembers, which might lead to a career performance reduction.

The literature supports a complex relationship between posttraumatic stress disorder (PTSD) and both injury severity and functional outcome. PTSD is associated with traumatic events such as a combat-related injury [12-13]. The onset of PTSD after a combat injury has been related to severity of injury, with the likelihood of a PTSD diagnosis more than three times greater in servicemembers with a severe injury than in those with a minor injury [14]. In addition, combat PTSD has been associated with impaired functional outcomes, including unemployment [15]. In a group of servicemembers who had been deployed, those reporting mental health concerns were more likely to leave military service within $1 \mathrm{yr}$ than those who did not report mental health concerns [16]. Because of the association between PTSD and injury severity, as well as between PTSD and functional outcome, PTSD may potentially play a role in the association between injury severity and career performance outcomes.

To our knowledge, there have been no studies published on career performance outcomes that focus specifically on combat blast injuries. The purpose of this retrospective cohort study was to describe career performance outcomes (i.e., disability-related discharge, time to discharge, early or normal attrition, pay grade changes) after injuries from a combat blast and to examine the relationship between the injury severity and type of discharge from service. We also examined servicemember demographics and the mechanism of blast across the injury severity groups. Because the development of PTSD is influenced by injury severity, and functional outcome is influenced by PTSD, we will investigate the effect of a PTSD diagnosis on the relationship between injury severity and type of service discharge.

\section{METHODS}

\section{Sample}

We identified the study sample from the Expeditionary Medical Encounter Database (EMED), formerly the NavyMarine Corps Combat Trauma Registry, which is maintained by the Naval Health Research Center (NHRC) in San Diego, California. The EMED contains information abstracted from U.S. servicemember medical records completed by military providers at far-forward medical treatment facilities (MTFs) near the point of injury through to theater hospitals. This information is merged with inpatient and outpatient medical record information and tactical, personnel, operational, and deployment-related data obtained from other U.S. Department of Defense databases [17].

Between March 2004 and December 2007, 4,324 male servicemembers sustained combat blast injuries that led to an encounter at a level 1 or 2 MTF. We excluded female servicemembers because of a low proportion of injured females $(n=59)$. Level 1 and 2 MTFs are far-forward or battlefield area units including immediate first-aid facilities (level 1) and units providing surgical resuscitation by forward mobile surgical teams (level 2). We defined a blast episode as a documented mechanism of injury, including an IED, grenade, RPG, land mine, aerial bomb, rocket, or mortar. Of the 4,324 potential study subjects, 36 died during the follow-up period and 33 did not match with the Career History Archival Medical and Personnel System (CHAMPS) database, which provided the outcome variable data. This left a final sample size of 4,255 male servicemembers.

\section{Procedures}

Trained clinical staff assigned clinical diagnosis codes from the International Classification of Diseases-9th Revision (ICD-9) to each injury described on the encounter form. In addition to assignment of diagnostic codes, severity of each injury was documented with two different standardized measures of injury severity: Abbreviated Injury Scale (AIS) and Injury Severity Score (ISS) [18]. The AIS is an anatomically based injury severity scale that scores each injury on a scale from 1 (relatively minor) to 6 
(untreatable) within six body regions (head, face, chest, abdomen, limbs, and external). The ISS is derived from the AIS scores from the three most severely injured body regions with a range of 0 to 75 and is an overall measure of injury severity [19]. We documented and categorized the ISS for each member into four severity levels: mild (1-3), moderate (4-8), serious (9-15), and severe $(\geq 16)$ [20-21].

\section{Measures}

We ascertained individual demographics (age, military rank, branch of service) and injury circumstances (type of blast) for each blast episode from the EMED. Age was reported in years and calculated by date of injury minus date of birth. We used the date of the first recorded medical encounter at the level 1 or 2 facility if the date of injury was not available. We categorized military rank as junior enlisted (E1-E3), midlevel enlisted (E4-E5), senior enlisted (E6-E9), or officers/warrant officers; military branch of service as Air Force, Army, Navy, or Marine Corps; and type of blast as IED, grenade, RPG, land mine, aerial bomb, or mortar.

We ascertained follow-up status through CHAMPS. CHAMPS is a database of career and medical information maintained by NHRC for Navy and Marine Corps Active Duty personnel from January 1, 1965, and personnel from all services from 1988 forward [22]. We determined the discharge type by examining discharge event codes and categorizing them as either a disability or nondisability. We defined disability discharge as a discharge event code with the term "disability" in the verbal description and nondisability discharge included all other event codes. Only the first discharge after the injury was used in the analysis if the servicemember reenlisted after discharge. We calculated time to discharge as discharge date minus date of injury. We directly ascertained each servicemember's current attrition status (Active Duty, normal attrition, early attrition) from CHAMPS. We defined early attrition as not completing obligated service [22], a broader category than disability discharge, including any circumstance requiring early release from service. In addition, not all disability discharge events were defined in CHAMPS as early attrition events. Pay grade changes used the difference between the last pay grade recorded prior to injury and the first pay grade change after injury. A PTSD diagnosis required documentation of the related ICD-9 code (309.81) in two separate medical records from either inpatient or outpatient visits with a visit date $>30 \mathrm{~d}$ after the date of injury. Servicemember records for this data set were updated in CHAMPS on September 30, 2009, resulting in a range of follow-up times from $1 \mathrm{yr}$ and 9 mo to $5 \mathrm{yr}$ and 5 mo.

\section{Data Analysis}

We compared demographics, injury characteristics, and follow-up status between the different injury severity categories defined by ISS. We compared categorical variables using chi square and mean values of continuous variables using a one-way analysis of variance. When we found differences in the means, we used a Bonferroni comparison to assess differences between the means. We also compared follow-up status between the PTSD diagnosis groups using chi square for the categorical variables and independent $t$-test for the continuous variable. To examine the relationship between demographics, injury characteristics, and follow-up status, we used univariate and multivariate logistic regression for the disability discharge outcome. The independent variable was injury severity, defined by the four ISS categories (mild [1-3], moderate [4-8], serious [9-15], and severe [ $\geq 16]$ ), and mild injury was the reference category. Age at time of injury (5 yr intervals) and time to discharge (1 yr intervals, for disability discharge only) were reported as independent variables as well as considered as covariates, along with branch of service (Marine Corps vs other), race (Caucasian vs other), and type of blast (IED vs other). We assessed interaction between severity and PTSD, and when found significant in the disability discharge outcome, the sample was stratified by PTSD diagnosis at least $30 \mathrm{~d}$ after injury. We assessed univariate and multivariate logistic regression models in the stratified samples. Level of significance was set at $p<0.05$ with interaction terms significant at $p<0.10$. All data analysis was completed using SAS version 9.2 (SAS Institute Inc; Cary, North Carolina).

\section{RESULTS}

We identified a total of 4,255 male servicemembers through the EMED who had an injury from a combat blast, survived the follow-up period (range of 1 yr and 9 mo to 5 yr and $5 \mathrm{mo}$ ), and could be matched to a CHAMPS record for outcome status. The majority of these servicemembers (2,588 [60.8\%]) had mild injuries (ISS score 1-3) (Table 1). There were $1,033(24.3 \%)$ servicemembers with moderate injuries (ISS category 4-8), 380 (8.9\%) with serious injuries 
Table 1.

Demographic and injury characteristics by Injury Severity Score (ISS) category among male servicemembers injured in combat-related blast $(N=$ 4,255) in Operation Iraqi Freedom, 2004-2007.

\begin{tabular}{|c|c|c|c|c|}
\hline Demographic & Mild $(n=2,588)$ & Moderate $(n=1,033)$ & Serious $(n=380)$ & Severe $(n=254)$ \\
\hline Age, yr (mean \pm SD) & $24.6 \pm 5.4$ & $24.5 \pm 5.2$ & $24.5 \pm 4.9$ & $24.8 \pm 5.4$ \\
\hline \multicolumn{5}{|l|}{ Race/Ethnicity, $n^{*}$ (\%) } \\
\hline Hispanic & 209 (8.1) & $80(7.7)$ & 37 (9.7) & $18(7.1)$ \\
\hline African American & 152 (5.9) & $70(6.8)$ & $17(4.5)$ & $14(5.5)$ \\
\hline Other & 179 (6.9) & $88(8.5)$ & $26(6.8)$ & $20(7.9)$ \\
\hline Junior Enlisted & $1,078(41.6)$ & 435 (42.1) & $152(40.0)$ & 91 (35.8) \\
\hline Midlevel Enlisted & $1,047(40.5)$ & $414(40.1)$ & $147(38.7)$ & $103(40.5)$ \\
\hline Senior Enlisted & 230 (8.9) & $90(8.7)$ & 33 (8.7) & $21(8.3)$ \\
\hline Officer/Warrant & $110(4.2)$ & $36(3.5)$ & $16(4.2)$ & $13(5.1)$ \\
\hline \multicolumn{5}{|c|}{ Branch of Service, ${ }^{\ddagger} n^{*}(\%)$} \\
\hline Air Force & $3(0.1)$ & $2(0.2)$ & $1(0.3)$ & $0(0.0)$ \\
\hline \multicolumn{5}{|l|}{ Type of Blast, ${ }^{\S} n^{*}$ (\%) } \\
\hline IED & 1,975 (76.3) & $858(83.0)$ & $285(75.0)$ & 198 (77.9) \\
\hline Mortar & $220(8.5)$ & $67(6.5)$ & 34 (8.9) & 30 (11.8) \\
\hline RPG & $132(5.1)$ & $41(4.0)$ & $14(3.7)$ & $9(3.5)$ \\
\hline Grenade & $123(4.7)$ & 20 (1.9) & $29(7.6)$ & $4(1.6)$ \\
\hline Land Mine & $105(4.1)$ & $36(3.5)$ & $10(2.6)$ & $12(4.7)$ \\
\hline Rocket & 31 (1.2) & $10(1.0)$ & $8(2.1)$ & $1(0.4)$ \\
\hline Aerial Bomb & $2(0.1)$ & $1(0.1)$ & $0(0.0)$ & $0(0.0)$ \\
\hline \multicolumn{5}{|c|}{$\begin{array}{l}\text { Note: Total ISS categories are mild (1-3), moderate (4-8), serious }(9-15) \text {, and severe }(\geq 16) \text {. } \\
{ }^{*} \text { Subject numbers for each variable do not add to total sample due to missing data. } \\
{ }^{\dagger} p \leq 0.05 \text {. } \\
{ }^{{ }^{*}} p<0.01 \\
{ }^{{ }} p<0.001 \\
\text { IED }=\text { improvised explosive device, RPG = rocket-propelled grenade, SD = standard deviation. }\end{array}$} \\
\hline
\end{tabular}

(ISS category 9-15), and 254 (6.0\%) with severe injuries (ISS category $\geq 16$ ). The average servicemember age was $24.6 \mathrm{yr}$ (standard deviation $=5.34$ ), the majority of the personnel were Caucasian, and the ISS levels did not vary by age or race/ethnicity. The majority of the servicemembers were Marines and either junior or midlevel enlisted. An IED was the most common blast mechanism, with the highest proportion in the moderate ISS category.

Table 2 presents the outcomes of type of discharge (disability, nondisability), attrition status (Active Duty, normal attrition, early attrition), pay grade changes (no change, increase, decrease), desertions, and PTSD diagnosis per ISS level. A total of 2,229 servicemembers (51.9\%) had a discharge code documented in CHAMPS and were catego- rized as either nondisability discharge $(1,565)$ or disability discharge (664). The shortest time to discharge was in the serious ISS severity level (544.6 d), which was significantly different from the longest time in the mild ISS level (661.9 d). The proportion of nondisability discharge and disability discharge across the ISS levels trend in opposite directions with the greatest percentage of nondisability discharges in the mildest severity level and the greatest percentage of disability discharge in the severe ISS level. When we examined attrition status, 53.9 percent $(2,295)$ of the servicemembers were Active Duty, 37.8 percent $(1,608)$ experienced normal discharge, and 8.3 percent (352) had an early discharge. The patterns in proportions across the ISS levels were similar in attrition status with the greatest 
Table 2.

Injury outcome follow-up status by Injury Severity Score (ISS) category among male servicemembers injured in combat-related blast $(N=4,255)$ in Operation Iraqi Freedom, 2004-2007.

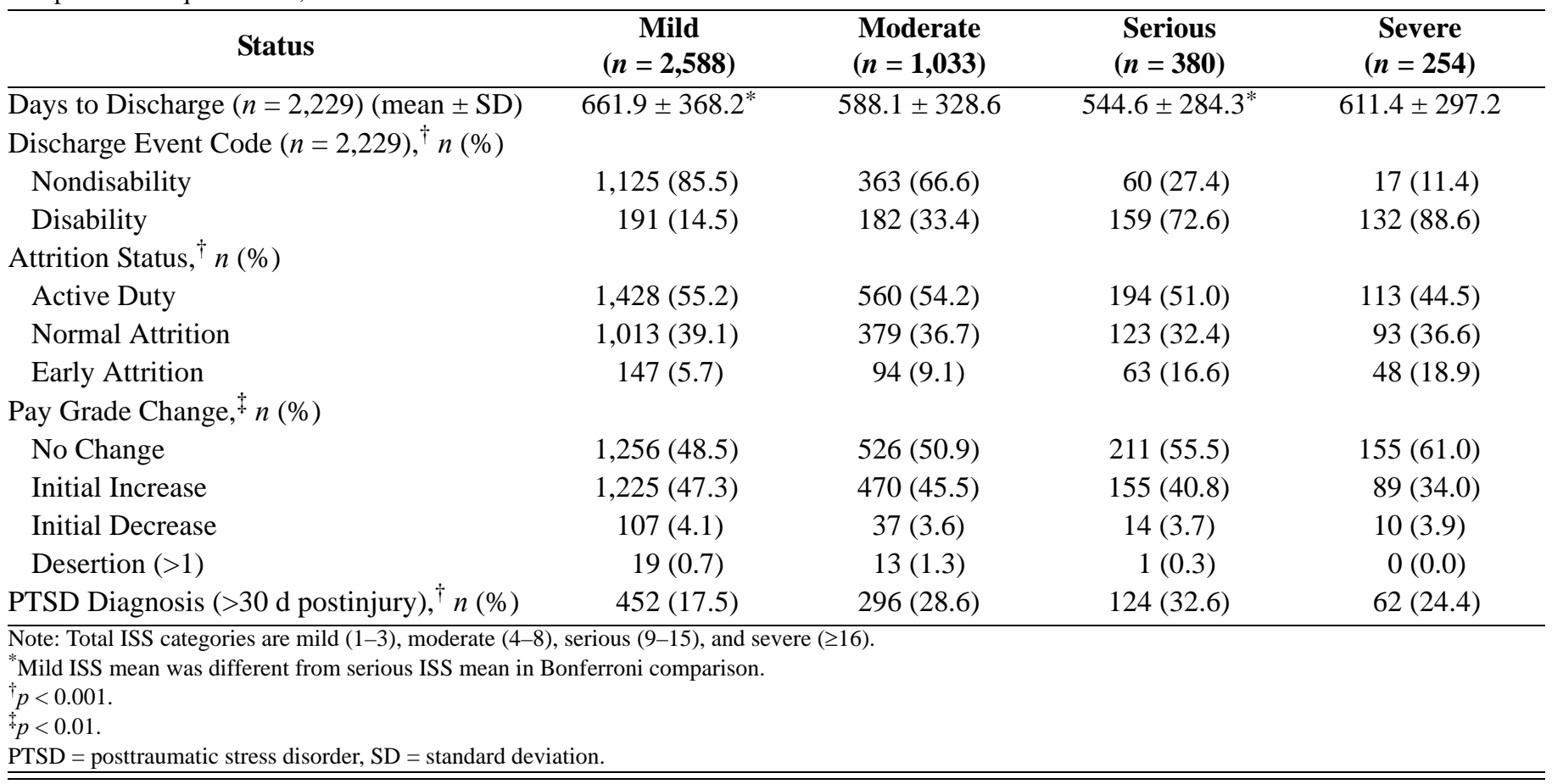

proportion of Active Duty and normal attrition in the mild ISS level and the greatest proportion of early attrition in the severe ISS level. This trend was also seen in pay grade changes, with the greatest proportion of pay grade increases in the mild ISS level, yet there is no discernible trend in those with pay grade decreases. The prevalence of PTSD across all severity levels was 21.9 percent, with the greatest proportion of PTSD diagnoses in the serious ISS level and the smallest proportion in the mild ISS level.

We examined the outcomes of type of discharge (disability, nondisability), attrition status (Active Duty, normal attrition, early attrition), pay grade changes (no change, increase, decrease) and desertions in relation to PTSD status (Table 3). The percentage of servicemembers with PTSD who were discharged with a disability was more than three times greater than those without PTSD (64.6\% vs $19.4 \%, p<0.001)$. Early attrition was also more common in those with PTSD than without PTSD $(12.5 \%$ vs $7.1 \%, p<0.001)$. There were also differences in pay grade changes between PTSD diagnostic groups, with any pay grade change (increase and decrease) more common in those with PTSD.

We used logistic regression to assess the relationship between severity level and disability discharge status with
Table 3.

Injury outcome follow-up status by posttraumatic stress disorder (PTSD) diagnosis among male servicemembers injured in combatrelated blast $(N=4,255)$ in Operation Iraqi Freedom, 2004-2007.

\begin{tabular}{lcc}
\hline \multicolumn{1}{c}{ Status } & $\begin{array}{c}\text { PTSD } \\
\text { Diagnosis } \\
(\boldsymbol{n}=\mathbf{9 3 4})\end{array}$ & $\begin{array}{c}\text { No PTSD } \\
\text { Diagnosis } \\
(\boldsymbol{n}=\mathbf{3 , 3 2 1})\end{array}$ \\
\hline $\begin{array}{l}\text { Days to Discharge* }(n=2,229)(\text { mean } \pm \text { SD) } \\
\text { Discharge Event Code }(n=2,229){ }^{*} n(\%)\end{array}$ & $706.0 \pm 328.3$ & $606.0 \pm 352.0$ \\
$\quad$ Nondisability & $181(35.3)$ & $1384(80.6)$ \\
$\quad$ Disability & $331(64.7)$ & $333(19.4)$ \\
Attrition Status, ${ }^{*} n(\%)$ & & \\
$\quad$ Active Duty & $522(55.9)$ & $1773(53.4)$ \\
$\quad$ Normal Attrition & $295(31.6)$ & $1313(39.5)$ \\
$\quad$ Early Attrition & $117(12.5)$ & $235(7.1)$ \\
Pay Grade Change, ${ }^{*} n(\%)$ & & \\
$\quad$ No Change & $405(43.4)$ & $1743(52.5)$ \\
$\quad$ Initial Increase & $480(51.4)$ & $1459(43.9)$ \\
$\quad$ Initial Decrease & $49(5.2)$ & $119(3.6)$ \\
$\quad$ Desertions $(>1)$ & $9(1.0)$ & $24(0.7)$ \\
\hline${ }^{*} p<0.001$. & & \\
SD = standard deviation. & & \\
\hline \hline
\end{tabular}

age, time to discharge, race, branch of service, type of blast, and PTSD diagnosis as covariates (Table 4). Both injury severity and PTSD diagnosis were significantly associated with disability discharge. In the multivariate 
Table 4.

Unadjusted and adjusted odds ratios (ORs) of disability discharge among male servicemembers injured from combat-related blast $(n=2,229)$ in Operation Iraqi Freedom, 2004-2007.

\begin{tabular}{lcc}
\hline \multicolumn{1}{c}{ Independent Variable } & $\begin{array}{c}\text { Unadjusted Model } \\
\text { OR (95\% CI) }\end{array}$ & $\begin{array}{c}\text { Adjusted Model } \\
\text { OR (95\% CI) }\end{array}$ \\
\hline Age (5 yr interval) & $0.90(0.79-1.02)$ & $0.84^{*}(0.72-0.98)$ \\
ISS Category & 1.00 & 1.00 \\
$\quad$ Mild & $2.95^{\dagger}(2.33-3.73)$ & $2.82^{\dagger}(2.16-3.70)$ \\
$\quad$ Moderate & $15.61^{\dagger}(11.17-21.80)$ & $19.00^{\dagger}(13.04-26.67)$ \\
$\quad$ Serious & $45.73^{\dagger}(26.98-77.53)$ & $66.88^{\dagger}(38.36-116.62)$ \\
$\quad$ Severe & $7.60^{\dagger}(6.12-9.44)$ & $9.98^{\dagger}(7.68-12.97)$ \\
PTSD Diagnosis (>30 d postinjury) & $1.01(0.92-1.11)$ & $1.02(0.89-1.16)$ \\
Time to Discharge (1 yr interval) & \\
\hline Note: Confounders include age, time to discharge, branch of service, race (Caucasian vs other), and type of blast (improvised explosive device vs other). Total ISS \\
categories are mild (1-3), moderate (4-8), serious (9-15), and severe $(\geq 16)$.
\end{tabular}

model, the odds of disability discharge in personnel with moderate injury severity level were nearly three times greater (odds ratio $[\mathrm{OR}]=2.82,95 \%$ confidence interval $[\mathrm{CI}]=2.16-3.70$ ) than in those with mild injury severity. There is a substantial increase in the odds of disability discharge in the serious ISS group $(\mathrm{OR}=19.00,95 \% \mathrm{CI}=$ 13.04-26.67) from the odds in the moderate injury severity level and again in the severe ISS group (OR $=66.88$, $95 \% \mathrm{CI}=38.36-116.62)$. The odds of disability discharge in servicemembers diagnosed with PTSD were nearly 10 times greater than in those without a PTSD diagnosis.
We assessed the interaction of PTSD and injury severity in a regression model with disability discharge as the outcome and all covariates in the model and found a significant interaction between PTSD and severity level categories $(p=0.01)$. We then stratified the sample by PTSD diagnosis for all further regression analyses using disability discharge as the outcome of interest. Table 5 presents the results of unadjusted and adjusted models for both PTSD diagnosis and no PTSD diagnosis groups. In the PTSD group, the odds of a disability discharge was over 50 percent greater $(\mathrm{OR}=1.83,95 \% \mathrm{CI}=1.20-2.80)$ in those with moderate severity level than those with a mild

Table 5.

Unadjusted and adjusted odds ratios (ORs) of disability discharge among male servicemembers injured from combat-related blast stratified by posttraumatic stress disorder (PTSD) diagnosis $>30$ d postinjury $(n=2,229)$ in Operation Iraqi Freedom, $2004-2007$.

\begin{tabular}{|c|c|c|c|c|}
\hline \multirow[b]{2}{*}{ Independent Variable } & \multicolumn{2}{|c|}{ PTSD Diagnosis $(n=512)$} & \multicolumn{2}{|c|}{ No PTSD Diagnosis $(n=1,717)$} \\
\hline & $\begin{array}{c}\text { Unadjusted Model } \\
\text { OR }(95 \% \text { CI) }\end{array}$ & $\begin{array}{l}\text { Adjusted Model } \\
\text { OR (95\% CI) }\end{array}$ & $\begin{array}{c}\text { Unadjusted Model } \\
\text { OR (95\% CI) }\end{array}$ & $\begin{array}{c}\text { Adjusted Model } \\
\text { OR (95\% CI) }\end{array}$ \\
\hline Age (5 yr interval) & $0.92(0.75-1.12)$ & $0.91(0.73-1.14)$ & $0.87(0.73-1.04)$ & $0.77^{*}(0.63-0.95)$ \\
\hline \multicolumn{5}{|l|}{ ISS Category } \\
\hline Mild & 1.00 & 1.00 & 1.00 & 1.00 \\
\hline Moderate & $1.84^{\dagger}(1.21-2.79)$ & $1.83^{\dagger}(1.20-2.80)$ & $3.76^{\dagger}(2.67-5.29)$ & $3.76^{\dagger}(2.66-5.31)$ \\
\hline Time to Discharge (1 yr interval) & $0.91(0.74-1.11)$ & $1.03(0.83-1.28)$ & $0.86^{*}(0.76-0.98)$ & $0.99(0.84-1.17)$ \\
\hline $\begin{array}{l}\text { Note: Confounders include age, time } t \\
\text { categories are mild (1-3), moderate }(4 \\
{ }^{*} p \leq 0.05 \text {. } \\
{ }^{+} p<0.001 . \\
{ }^{\dagger} p<0.01 . \\
\text { CI }=\text { confidence interval, ISS = Injury }\end{array}$ & $\begin{array}{l}\text { harge, branch of servi } \\
\text { erious (9-15), and sev } \\
\text { ity Score. }\end{array}$ & $\begin{array}{l}\text { (Caucasian vs other), } \\
6) .\end{array}$ & & \\
\hline
\end{tabular}


severity level. While the odds of a disability discharge increased substantially in the serious and severe ISS levels $(\mathrm{OR}=14.18,95 \% \mathrm{CI}=5.50-36.56$; and $\mathrm{OR}=13.35$, $95 \% \mathrm{CI}=4.01-44.46$, respectively), the odds of a disability discharge were not different between the two highest severity levels. This was in contrast to the no PTSD diagnosis group, in which the odds of disability discharge increased with each increase in ISS level, with the odds of disability discharge over 90 times greater in those with severe ISS level injury than those with a mild injury (OR $=94.91,95 \%$ CI $=$ 50.90-176.98). The Figure shows a graphical representation of these ORs.

\section{DISCUSSION}

Because blasts have been the primary mechanism of injury in OIF/OEF, understanding potential career performance outcomes and injury-related risk factors associated with those outcomes is important in the planning of medical and follow-up care for injured servicemembers. This study found an increasing proportion of both disability discharge and early attrition and decreasing proportion of pay grade increases as injury severity level increased, yet these trends were most pronounced in the disability discharge outcome. The dose-dependent relationship of injury severity to dis-

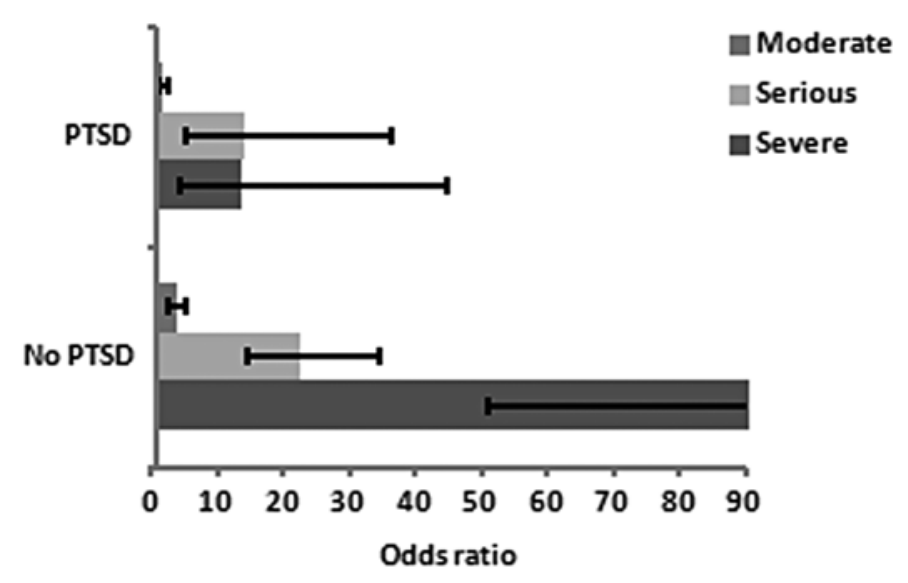

Figure.

Odds ratios of disability discharge due to injury severity (mild severity reference) by posttraumatic stress disorder (PTSD) diagnosis. Error bars represent 95 percent confidence intervals of odds ratio. Previously published in: Eskridge SL. Combatrelated blast injuries: Injury types and outcomes [dissertation]. [San Diego]: San Diego State University and University of California, San Diego; 2011. ability discharge was particularly evident in the absence of concomitant PTSD. Career indicators, especially disability discharge, should continue to be considered within the overall spectrum of blast injury functional outcomes and should be incorporated into the evaluation and refinement of rehabilitation strategies.

To our knowledge, this study was the first to examine career performance outcomes in a large cohort of servicemembers injured by combat-related blasts. While there have been studies investigating military discharge as an outcome in servicemembers who experienced a TBI [2324], this information has not been reported in servicemembers experiencing the wide spectrum of injuries from combat-related blasts. Other studies have focused on PTSD and outcomes of military discharge and employment status but not how injury severity relates to these outcomes with and without the diagnosis of PTSD [15-16].

The prevalence of PTSD was consistent with previous literature [13,16], and PTSD was associated with injury severity, early attrition, disability discharge, and pay grade changes. After stratifying the sample by PTSD diagnosis, we found clear differences between the groups in the relationship between injury severity and disability discharge. In the group without a PTSD diagnosis, we found a doseresponse relationship between injury severity and disability discharge, with the odds of an adverse outcome increasing with a greater severity level. However, while injury severity is associated with disability discharge in the PTSD group, the pattern is less obvious and dramatic. These differences in the influence of injury severity on outcome may be because of the mental health burden caused by PTSD. During injury recovery without PTSD, servicemembers need to overcome physical impairments to achieve the highest level of function. Those with PTSD must overcome both physical and psychological impairments, which may lessen the influence of injury severity on eventual outcome. Additionally, PTSD can occur in mild and moderate injuries, which might result in mental health-related disability discharge.

Strengths of this study include a large cohort of injured male servicemembers with point-of-injury documentation, including all levels of injury severity. Followup time was sufficient to allow an adequate number of discharges to occur for analysis, and outpatient diagnoses were completed by medical providers rather than by selfreport, which reduced the influence of recall bias. The criteria for PTSD diagnosis required the documentation of PTSD diagnosis by a medical practitioner at a minimum 
of two separate clinic visits at least $30 \mathrm{~d}$ after injury, which reduced the likelihood of misclassification.

While the collection of medical encounter documentation from level 1 and 2 MTFs continues to improve for the EMED, the coverage of all injured servicemembers is not complete. Missing records occur for various reasons, including not visiting an MTF for care, rapid evacuation with limited time for documentation, and incomplete coverage of all MTFs. Because the MTFs covered are primarily Navy-Marine Corps facilities, Army and Air Force personnel may be underrepresented in the study population. In addition to incomplete coverage of all injured servicemembers, documentation of a medical encounter on printed or electronic forms may be incomplete, which would reduce the accuracy of injury severity assessment. There are also limitations in the use of ISS as a proxy for injury severity because one number is used to describe a variety of injuries across anatomical locations [20]. The same ISS score could represent multiple different combinations of injury types and locations and any error in AIS scoring may translate to an incorrect ISS score. Categorizing ISS into discrete severity levels improves accuracy but the potential for misclassification bias still remains.

\section{CONCLUSIONS}

With the high proportion of injuries caused by blasts in the current conflicts, long-term care and career management of servicemembers with blast-related injuries are currently, and will continue to be, a challenge. This study demonstrates that initial injury severity is associated with adverse career performance outcomes, in particular disability discharge, and the relationship in servicemembers with PTSD is more complex than in those without a PTSD diagnosis. A model of career retention must consider the effect PTSD has on postrehabilitative performance beyond the influence of the injury itself.

\section{ACKNOWLEDGMENTS}

\section{Author Contributions:}

Study concept and design: S. L. Eskridge, C. A. Macera, T. L. Holbrook, S. I. Woodruff, D. J. Morton, R. A. Shaffer.

Acquisition of data: M. R. Galarneau.

Analysis and interpretation of data: S. L. Eskridge.

Drafting of manuscript: S. L. Eskridge.

Critical revision of manuscript for important intellectual content:

C. A. Macera, M. R. Galarneau, S. I. Woodruff, A. J. MacGregor.

Obtained funding: M. R. Galarneau.
Administrative support: M. R. Galarneau.

Financial Disclosures: The authors have declared that no competing interests exist.

Funding/Support: This material was based on work supported by the U.S. Navy Bureau of Medicine and Surgery under the Wounded, Ill and Injured/Psychological Health/Traumatic Brain Injury Program (Work Unit No. 60808).

Institutional Review: This research has been conducted in compliance with all applicable Federal regulations governing the protection of human subjects in research and approved by the NHRC Institutional Review Board (Protocol No. NHRC.2009.0023).

Participant Follow-Up: The authors do not plan to inform the participants of the publication of this study due to a lack of contact information. Disclaimer: The views expressed in this article are those of the authors and do not reflect the official policy or position of the Department of the Navy, Department of Defense, or U.S. Government.

\section{REFERENCES}

1. Owens BD, Kragh JF Jr, Wenke JC, Macaitis J, Wade CE, Holcomb JB. Combat wounds in Operation Iraqi Freedom and Operation Enduring Freedom. J Trauma. 2008;64(2): 295-99. [PMID:18301189] http://dx.doi.org/10.1097/TA.0b013e318163b875

2. Ritenour AE, Blackbourne LH, Kelly JF, McLaughlin DF, Pearse LA, Holcomb JB, Wade CE. Incidence of primary blast injury in US military overseas contingency operations: a retrospective study. Ann Surg. 2010;251(6):1140-44.

[PMID:20485126]

http://dx.doi.org/10.1097/SLA.0b013e3181e01270

3. Gondusky JS, Reiter MP. Protecting military convoys in Iraq: an examination of battle injuries sustained by a mechanized battalion during Operation Iraqi Freedom II. Mil Med. 2005;170(6):546-49. [PMID:16001610]

4. Champion HR, Holcomb JB, Young LA. Injuries from explosions: physics, biophysics, pathology, and required research focus. J Trauma. 2009;66(5):1468-77. [PMID:19430256] http://dx.doi.org/10.1097/TA.0b013e3181a27e7f

5. DePalma RG, Burris DG, Champion HR, Hodgson MJ. Blast injuries. N Engl J Med. 2005;352(13):1335-42.

[PMID:15800229] http://dx.doi.org/10.1056/NEJMra042083

6. Ling G, Bandak F, Armonda R, Grant G, Ecklund J. Explosive blast neurotrauma. J Neurotrauma. 2009;26(6):815-25. [PMID:19397423] http://dx.doi.org/10.1089/neu.2007.0484

7. U.S. Department of Defense. Department of Defense directive number 6025.21E: Medical research for prevention, mitigation, and treatment of blast injuries. Washington (DC): U.S. Department of Defense; 2006.

8. Peleg K, Aharonson-Daniel L, Stein M, Michaelson M, Kluger Y, Simon D, Noji EK; Israeli Trauma Group (ITG). 
Gunshot and explosion injuries: characteristics, outcomes, and implications for care of terror-related injuries in Israel. Ann Surg. 2004;239(3):311-18. [PMID:15075646] http://dx.doi.org/10.1097/01.sla.0000114012.84732.be

9. Mernoff ST, Correia S. Military blast injury in Iraq and Afghanistan: the Veterans Health Administration's polytrauma system of care. Med Health R I. 2010;93(1):16-18,21. [PMID:20481201]

10. Lew HL, Poole JH, Vanderploeg RD, Goodrich GL, Dekelboum S, Guillory SB, Sigford B, Cifu DX. Program development and defining characteristics of returning military in a VA Polytrauma Network Site. J Rehabil Res Dev. 2007; 44(7):1027-34. [PMID:18075959] http://dx.doi.org/10.1682/JRRD.2007.05.0073

11. Scott SG, Belanger HG, Vanderploeg RD, Massengale J, Scholten J. Mechanism-of-injury approach to evaluating patients with blast-related polytrauma. J Am Osteopath Assoc. 2006;106(5):265-70. [PMID:16717367]

12. Hoge CW, McGurk D, Thomas JL, Cox AL, Engel CC, Castro CA. Mild traumatic brain injury in U.S. soldiers returning from Iraq. N Engl J Med. 2008;358(5):453-63. [PMID:18234750] http://dx.doi.org/10.1056/NEJMoa072972

13. Koren D, Norman D, Cohen A, Berman J, Klein EM. Increased PTSD risk with combat-related injury: a matched comparison study of injured and uninjured soldiers experiencing the same combat events. Am J Psychiatry. 2005; 162(2):276-82. [PMID:15677591] http://dx.doi.org/10.1176/appi.ajp.162.2.276

14. MacGregor AJ, Corson KS, Larson GE, Shaffer RA, Dougherty AL, Galarneau MR, Raman R, Baker DG, Lindsay SP, Golomb BA. Injury-specific predictors of posttraumatic stress disorder. Injury. 2009;40(9):1004-10. [PMID:19524912] http://dx.doi.org/10.1016/j.injury.2009.04.006

15. Zatzick DF, Marmar CR, Weiss DS, Browner WS, Metzler TJ, Golding JM, Stewart A, Schlenger WE, Wells KB. Posttraumatic stress disorder and functioning and quality of life outcomes in a nationally representative sample of male Vietnam veterans. Am J Psychiatry. 1997;154(12):1690-95. [PMID:9396947]

16. Hoge CW, Auchterlonie JL, Milliken CS. Mental health problems, use of mental health services, and attrition from military service after returning from deployment to Iraq or Afghanistan. JAMA. 2006;295(9):1023-32. [PMID:16507803] http://dx.doi.org/10.1001/jama.295.9.1023

17. Galarneau MR, Hancock WC, Konoske P, Melcer T, Vickers RR, Walker GJ, Zouris JM. The Navy-Marine Corps Combat Trauma Registry. Mil Med. 2006;171(8):691-97. [PMID:16933807]

18. Gennarelli T, Wodzon E, editors. Abbreviated Injury Scale 2005. 7th rev. Barrington (IL): Association for the Advancement of Automotive Medicine; 2007.
19. Baker SP, O’Neill B, Haddon W Jr, Long WB. The Injury Severity Score: a method for describing patients with multiple injuries and evaluating emergency care. J Trauma. 1974; 14(3):187-96. [PMID:4814394] http://dx.doi.org/10.1097/00005373-197403000-00001

20. Copes WS, Champion HR, Sacco WJ, Lawnick MM, Keast SL, Bain LW. The Injury Severity Score revisited. J Trauma. 1988;28(1):69-77. [PMID:3123707] http://dx.doi.org/10.1097/00005373-198801000-00010

21. Linn S, Linn R, Sheps S, Sarid M, Michaelson M, Geva H, Wiener M, Brandes JM, Revach M. Injury severity scoring and length of stay in hospital of war casualties-demonstration of an association and possible selection bias. Int J Epidemiol. 1993;22(5):905-10. [PMID:8282471] http://dx.doi.org/10.1093/ije/22.5.905

22. Gunderson EK, Garland CF, Miller MR, Gorham ED. Career History Archival Medical and Personnel System. Mil Med. 2005;170(2):172-75. [PMID:15782842]

23. Galarneau MR, Woodruff SI, Dye JL, Mohrle CR, Wade AL. Traumatic brain injury during Operation Iraqi Freedom: findings from the United States Navy-Marine Corps Combat Trauma Registry. J Neurosurg. 2008;108(5):950-57.

[PMID:18447712]

http://dx.doi.org/10.3171/JNS/2008/108/5/0950

24. Ommaya AK, Salazar AM, Dannenberg AL, Ommaya AK, Chervinsky AB, Schwab K. Outcome after traumatic brain injury in the U.S. military medical system. J Trauma. 1996; 41(6):972-75. [PMID:8970548] http://dx.doi.org/10.1097/00005373-199612000-00005

Submitted for publication January 4, 2012. Accepted in revised form May 25, 2012.

This article and any supplementary material should be cited as follows:

Eskridge SL, Macera CA, Galarneau MR, Holbrook TL, Woodruff SI, MacGregor AJ, Morton DJ, Shaffer RA. Combat blast injuries: Injury severity and posttraumatic stress disorder interaction on career outcomes in male servicemembers. J Rehabil Res Dev. 2013;50(1):7-16. http://dx.doi.org/10.1682/JRRD.2012.01.0004

ResearcherID: Susan L. Eskridge, PT, PhD: G-1665-2011

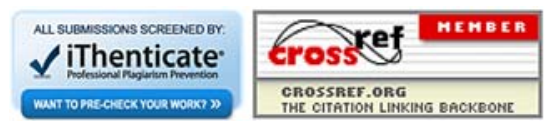


